\title{
Offsite consequence analysis of liquefied chlorine gas spill at a water treatment plant in Malaysia
}

\begin{abstract}
Malaysia, like any other country has experienced a number of chemical accidents in the past, hence the necessity to undertake thorough consequence analysis to mitigate similar occurrences in future. The water treatment plant in question keeps more than 18.6 MT (metric tonnes) of chlorine to disinfect water for the community in municipal area. However, chlorine is a hazardous chemical that can cause serious injuries, loss of life and damage to properties and environment if not handled properly. Hence using the Environmental Protection Agency (EPA) methodology an offsite consequence analysis was conducted to determine the potential impacts in the event of catastrophic release of chlorine at the water treatment plant. A "worstcase release scenario" and "alternative scenario" were developed for the treatment plant. The results obtained from the use of TRACE software showed that a potential hazard exists, even under average annual weather conditions. Within a $6 \mathrm{~km}$ radius, an estimated number of 102 000 people within the zone for a $3 \mathrm{ppm}$ chlorine exposure may be affected due to a worstcase release. The consequence isopleth for the respective chlorine concentration indicates that the chlorine plume is directed towards the administration building and process unit facilities of the plant. Hence, it is critical to ensure that all personnel within the plant are provided with sufficient training on the emergency response plan and the application of the relevant personnel protective equipment (PPE) in the event of accidental releases. Although the hazard exists, the risk to the public may be low. An alternative release scenario would be limited due to the use of safety and mitigation systems incorporated into the chlorinating system, but the plant requires other supporting safety measures to supplement the existing facility's inherent safety. Such measures are essential to ensure that in the event of a potential incident at the plant onsite and offsite effects could be minimised to ensure the risk is as low as reasonably practicable (ALARP).
\end{abstract}

Keyword: Safety; Chlorine; Leak; Consequence modelling; Water treatment plant 